\title{
Anxiety associated with colposcopy at Chris Hani Baragwanath Hospital, Johannesburg
}

M Y H Moosa, FCPsych, MMed (Psych)

Department of Psychiatry, University of the Witwatersrand, Johannesburg

L Chait, A Cohen, L Diamond, J Dunlop, M Masela, T Matlhatsi, T E Mehlomakhulu, J Naidu, B Ngutshane, P Vythilingum

GEMP III students 2008, Faculty of Health Sciences, University of the Witwatersrand

Given the high incidence of cervical cancer in South Africa and the distress it causes, we aimed to determine the extent of anxiety in patients undergoing colposcopy at Chris Hani Baragwanath (CHB) Hospital, Johannesburg.

Method. A descriptive and cross-sectional study design was applied on a convenient sample of patients from the waiting area of the colposcopy clinic at CHB Hospital. Females attending a first colposcopy appointment were invited to participate by completing the State-Trait Anxiety Inventory (STAIl) after written informed consent had been obtained

Results. Among a total of 31 women, the mean STAI score for state anxiety was 46.77 (SD=12.92) and the mean STAI score for trait anxiety was 46.81 (SD=9.50); $51.6 \%$ of the patients had a STAI state anxiety score of $>50$, while $41.9 \%$ of the patients had a STAI trait anxiety score $>50$. There was no significant association between either elevated STAI state or trait anxiety scores and age group $\left(\chi^{2}=1.77 ; p=0.18\right.$ and $\chi^{2}=0.001 ; p=0.98$, respectively); marital status $\left(\chi^{2}=0.301\right.$; $p=0.58$ and $\chi^{2}=0.834 ; p=0.36$ ); level of education $\left(\chi^{2}=0.444 ; p=0.51\right.$ and $\left.\chi^{2}=2.40 ; p=0.12\right)$; employment status $\left(\chi^{2}=1.78 ; p=0.18\right.$ and $\left.\chi^{2}=0.001 ; p=0.98\right)$; monthly income $\left(\chi^{2}=1.15 ; p=0.28\right.$ and $\left.\chi^{2}=0.03 ; p=0.86\right)$ or using stimulants $\left(\chi^{2}=0.416 ; p=0.52\right.$ and $\left.\chi^{2}=0.394 ; p=0.53\right)$. There was a significant negative correlation between age and STAI state anxiety scores $\left(r^{2}=0.004 ; p=0.017\right)$ and $a$ positive correlation between age and STAI trait anxiety scores $\left(r^{2}=0.004 ; p=0.019\right)$

Conclusion. This study reported significantly elevated trait anxiety scores relating to colposcopy and emphasises the need to identify the anxiety and institute a plan to ameliorate it with information booklets, leaflets, video colposcopy and educational counselling.
Cervical cancer is a disease with particular relevance to the psychiatrist doing consultation-liaison work, whose role is that of a link between psychiatry and other disciplines. 1,2 Like most medical conditions or surgical interventions it has potentially significant psychological impact, for the burden of being aware that one is ill may be increased by concerns and worries about the illness and its effect on one's life and quality of life, including social, familial and occupational roles. Medical and/or surgical interventions may add to the patient's discomfort, concerns and worries, as she may face intrusive investigations, side-effects of medication, and a painful operation, which she may perceive as mutilating, and its sequelae.

To screen for cervical cancer and its precursor abnormal cells in the tissues of the cervix, regular cervical smears should be done.,4 A colposcopy is performed when a cervical smear has revealed the presence of abnormal cells. It aids in the identification of abnormal cells in the transformation zone where cervical neoplasia originates ${ }^{5}$ and aids in obtaining a biopsy. ${ }^{6}$ However, despite recent advances through cervical smears and colposcopy examinations mortality from cervical cancer remains high. ${ }^{5}$ Adherence to follow-up appointments is poor, leading to delayed diagnosis and/or treatment. A possible reason for the poor adherence may be anxiety associated with the procedure and/or its outcome.

State anxiety is a transitory emotional state or condition characterised by subjective, consciously perceived feelings of tension and apprehension, and heightened autonomic nervous system activity.? State anxiety may fluctuate over time and can vary in intensity. In contrast, trait anxiety denotes relatively stable individual differences in anxiety proneness and refers to a general tendency to respond with anxiety to perceived threats in the environment.

Marteau and Walker ${ }^{8}$ reported that a significant proportion of patients attending colposcopy clinics experienced anxiety related to the procedure, i.e. state anxiety. A study done on 149 women in New Brunswick, Canada, showed these levels of anxiety to be particularly high. ${ }^{9}$ High levels of anxiety before colposcopy can have adverse consequences, including pain and discomfort during the procedure and a high rate of default (failure to attend the procedure and loss to follow-up). ${ }^{4}$ Nugent et al. ${ }^{9}$ reported that anxiety was most extreme in younger women who knew less 
about the procedure and had more concurrent stressors in their lives.

Because of the high incidence of cervical cancer in South Africa, colposcopies in public hospitals are largely conducted in large numbers and under less than ideal circumstances. To our knowledge, there are few published data on anxiety in these patients, so there is a need to assess this problem with the aim of ameliorating it and thereby improving adherence. It is also important for consultation-liaison psychiatrists in the general hospital to be aware of the psychological impact of what appear to be minor procedures, so that they can bring it to the attention of their colleagues in other disciplines and work closely with them in addressing it effectively.

The aim of this study was to determine the extent of anxiety experienced by women undergoing colposcopy at Chris Hani Baragwanath (CHB) Hospital, Johannesburg. This study may form a baseline for subsequent studies looking at possible ways to reduce the anxiety associated with colposcopy.

\section{Methods}

We performed a descriptive and cross-sectional study of a convenient sample of patients from the waiting area of the colposcopy clinic at CHB hospital. Thirty-one women, all aged over 18 years and attending their first colposcopy appointment, agreed to participate in the study. After the patients had given written informed consent, demographic characteristics were obtained from them and they completed the State-Trait Anxiety Inventory (STAI). Interviews were conducted on a one-on-one basis, in a private room, to limit peer influence both from the other interviewers and from the patients.

The STAl is a self-report assessment device that consists of separate measures for state and trait anxiety, respectively. For the trait anxiety scale the stability coefficients ranged from 0.65 to 0.86 in a validation study of the STAI, whereas the range for the state anxiety scale was 0.16 to 0.62 . $^{7}$ This low level of stability for the state anxiety scale is expected, since responses to the items on this scale are meant to reflect the influence of transient situational factors at the time of testing. Validity correlations between this scale and other measures of trait anxiety were 0.80, 0.75, and O.52 for the Taylor Manifest Anxiety Scale, the IPAT Anxiety Scale and the Multiple Affect Adjective Check List, respectively.

The STAI consists of 20 items to assess state anxiety and another 20 items to assess trait anxiety. These two parts differ in item wording, response format (intensity $v$. frequency), and the instructions on how to respond

Twenty statements each with four possible responses make up form Y-1, which shows the subject's state anxiety Itransitory condition of unpleasant, consciously perceived feelings of tension, apprehension and nervousness that vary in intensity and fluctuate in time as a reaction to circumstances that are perceived as threatening). On the reverse of the page a further 20 statements, again each with 4 possible responses, make up form Y-2, which indicates the subject's trait anxiety (relatively stable individual differences that are impermeable to situational stresses, i.e. how the respondent generally feels). Each STAI response option has a weighted score of 1 - 4. To obtain scores for the state anxiety and trait anxiety scales the weighted scores were added for the 20 items that make up each scale. The combined scores for each scale can vary from a minimum of 20 to a maximum of 80 . A score of above $40.4 \pm 10.15$ indicates above-normal anxiety levels (i.e. a score of $40.4 \pm 10.15$ on form $Y$ - 1 indicates the likely presence of state anxiety, and a score of $40.4 \pm 10.15$ on form Y-2 indicates the likely presence of trait anxiety).

Women who were experiencing high levels of anxiety were offered psychological evaluation through a referral system involving the Department of Psychiatry at CHB. Ethical approval for the study was obtained from the Human Research Ethics Committee of the University of the Witwatersrand, Johannesburg.

Descriptive statistics were computed as means and frequencies. The two-tailed paired ttest was used to compare continuous characteristics. Comparisons were examined by the use of contingency tables (chi-square test with Yates correction). Data were computed and interpreted with the help of Microsoft Excel, the N-Stat programme and the EPI Info 2002 analysis programme.

\section{Results}

A total of 31 women participated in this study. The majority were residents of Soweto (the referral hospital for which is $\mathrm{CHB}$ Hospital). Their median age was 37 years $195 \%$ lower confidence level $=32 ; 95 \%$ upper confidence level $=42$ ), with a range of 25 - 56 years (Fig. 1).

The majority of the participants were in the age group $31-45$ years (64.5\%); were single, divorced or separated (90.3\%); had a secondary or higher level of education (90.3\%); were unemployed (61.3\%); and were receiving a monthly income of 


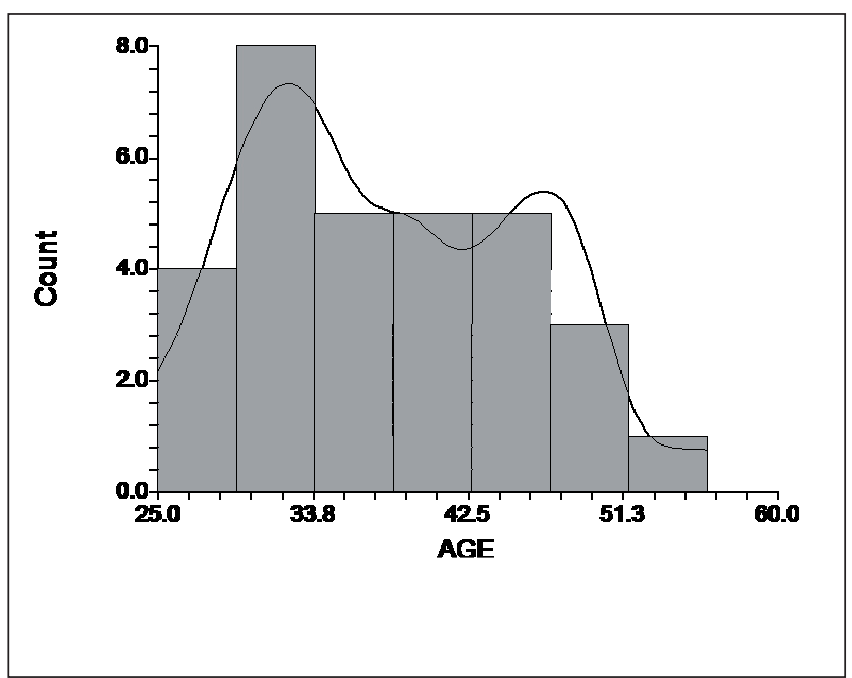

Fig. 1. Histogram of patient age distribution.

$<$ R 1000 (71.0\%) (Table I). One out every 3 patients was using stimulants, of which the most common was caffeine.

The mean STAl score for state anxiety was 46.77 (SD=12.92), with the lowest score 20 and the highest 69, and the mean STAI score for trait anxiety was 46.81 (SD=9.50), with the scores ranging from 25 to 62 . Of the patients $51.6 \%$ had a STAI state anxiety score of $>50$ labove the maximum range to confirm the presence of state anxiety) and $41.9 \%$ a trait anxiety score $>50$.

There was no significant association between either elevated STAI state or trait anxiety scores and age group $\left(\chi^{2}=1.77 ; p=0.18\right.$ and $\chi^{2}=0.001 ; p=0.98$, respectively); marital status $\left(\chi^{2}=0.301\right.$; $p=0.58$ and $\left.\chi^{2}=0.834 ; p=0.36\right)$; level of education $\left(\chi^{2}=0.444\right.$; $p=0.51$ and $\left.\chi^{2}=2.40 ; p=0.12\right)$; employment status $\left(\chi^{2}=1.78\right.$; $p=0.18$ and $\left.\chi^{2}=0.001 ; p=0.98\right)$; monthly income $\left(\chi^{2}=1.15\right.$; $p=0.28$ and $\left.\chi^{2}=0.03 ; p=0.86\right)$ or using stimulants $\left(\chi^{2}=0.416\right.$; $p=0.52$ and $\chi^{2}=0.394 ; p=0.53$.

There was a significant negative correlation between age and STAI state anxiety scores $\left(r^{2}=0.004 ; p=0.017\right)$ (Fig. 2) and a positive correlation between age and STAI trait anxiety scores $\left(r^{2}=0.004 ; p=0.019\right)$ (Fig. 3).

\section{Discussion}

A colposcopy is done following a positive cervical smear. It may confirm the diagnosis of cervical cancer, which has high morbidity and mortality. Women undergoing this procedure would therefore be expected to have high levels of anxiety related to both the

Table I. Characteristics of the study population in relation to STAI scores

\begin{tabular}{|c|c|c|c|c|c|}
\hline \multirow[b]{2}{*}{ Variables } & \multirow{2}{*}{$\begin{array}{l}\text { Total } \\
\text { population } \\
(N=31)\end{array}$} & \multicolumn{2}{|c|}{ STAI state scores } & \multicolumn{2}{|c|}{ STAI trait scores } \\
\hline & & $>50(N=16)$ & $<50(N=15)$ & $>50(N=13)$ & $<50(N=18)$ \\
\hline \multicolumn{6}{|l|}{ Age group (yrs) } \\
\hline$<30$ & 4 & $2(50 \%)$ & $2(50 \%)$ & $1(25 \%)$ & $3(75 \%)$ \\
\hline $31-45$ & 20 & $12(60 \%)$ & $8(40 \%)$ & $9(45 \%)$ & $11(55 \%)$ \\
\hline$>45$ & 7 & $2(28.6 \%)$ & $5(71.4 \%)$ & $3(42.9 \%)$ & $4(57.1 \%)$ \\
\hline \multicolumn{6}{|l|}{ Marital status } \\
\hline Single/ divorced & 28 & $14(50 \%)$ & $14(50 \%)$ & $11(39.3 \%)$ & $17(60.7 \%)$ \\
\hline Married/cohabiting & 3 & $2(66.7 \%)$ & $1(33.3 \%)$ & $2(66.7 \%)$ & $1(33.3 \%)$ \\
\hline \multicolumn{6}{|l|}{ Level of education } \\
\hline Less than secondary & 3 & $1(33.3 \%)$ & $2(66.7 \%)$ & $0(0 \%)$ & $3(100 \%)$ \\
\hline Secondary or higher & 28 & $15(53.6 \%)$ & $13(46.4 \%)$ & $13(46.4 \%)$ & $15(53.6 \%)$ \\
\hline \multicolumn{6}{|l|}{ Employed } \\
\hline Yes & 12 & $8(66.7 \%)$ & $4(33.3 \%)$ & $5(41.7 \%)$ & $7(58.3 \%)$ \\
\hline No & 19 & $8(42.1 \%)$ & $11(57.9 \%)$ & $8(42.1 \%)$ & $11(57.9 \%)$ \\
\hline \multicolumn{6}{|l|}{ Monthly income } \\
\hline$<$ R1 000 & 22 & $10(45.5 \%)$ & $12(54.5 \%)$ & 9 (40.9\%) & $13(59.1 \%)$ \\
\hline$>\mathrm{R} 1000$ & 9 & $6(66.7 \%)$ & $3(33.3)$ & $4(44.4 \%)$ & $5(55.6 \%)$ \\
\hline \multicolumn{6}{|l|}{ Currently on medication } \\
\hline Yes & 19 & $8(42.1 \%)$ & $11(57.9 \%)$ & $8(42.1 \%)$ & $11(57.9 \%)$ \\
\hline No & 12 & $8(66.7 \%)$ & $4(33.3 \%)$ & $5(41.7 \%)$ & $7(58.3 \%)$ \\
\hline \multicolumn{6}{|l|}{ Currently using stimulants } \\
\hline Yes & 10 & $6(60 \%)$ & $4(40 \%)$ & $5(50 \%)$ & $5(50 \%)$ \\
\hline No & 21 & $10(47.6 \%)$ & $11(52.4 \%)$ & $8(38.1 \%)$ & $13(61.9 \%)$ \\
\hline
\end{tabular}




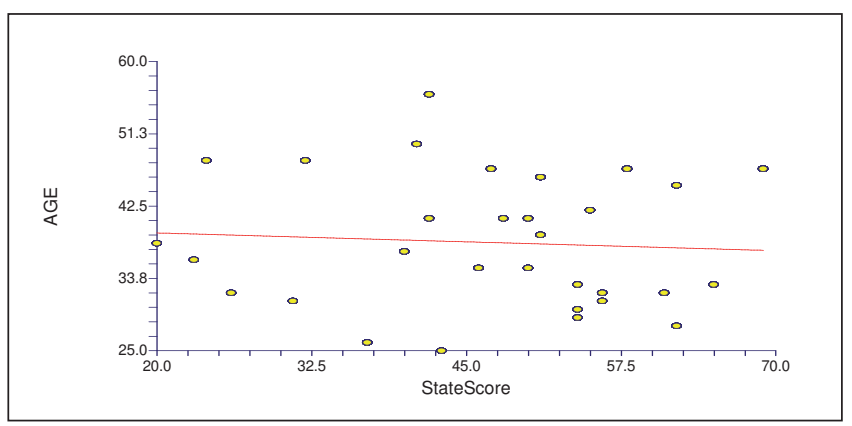

Fig. 2. Linear regression plot of state anxiety scores v. age.

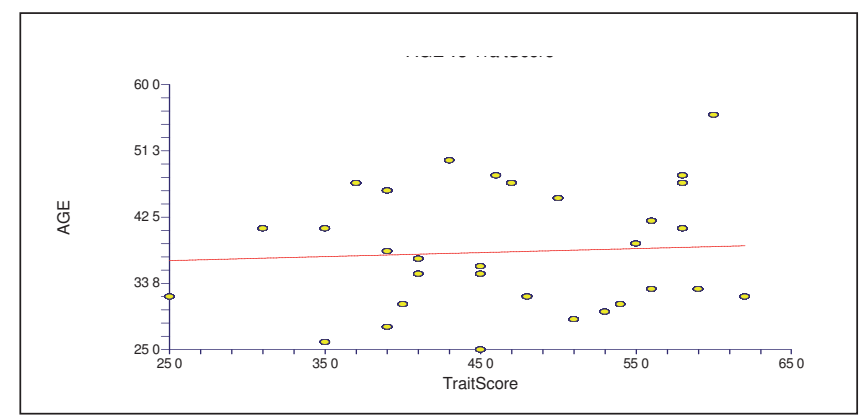

Fig. 3. Linear regression plot of trait anxiety scores $v$. age.

actual procedure and its outcome. This was found by Marteau and Walker ${ }^{8}$ in 1990 and Nugent et al. ${ }^{9}$ in 1993.

In this study of patients undergoing colposcopy at $\mathrm{CHBH}$, using the STAI, the mean state anxiety score was 46.8 (SD=12.9). While the actual scores were higher than those reported in other studies the mean was similar to the 42.7 (SD=12.3) reported by Hellsten et al. ${ }^{10}$ Further, half the patients $(51 \%)$ had scores higher than 50, indicating the likely presence of state anxiety, i.e. anxiety as a direct consequence of undergoing colposcopy.

It is likely that some of the patients were anxious because they were unsure of what the procedure entails, while those who did know what to expect may have been worried about pain, discomfort or embarrassment from such an invasive procedure. These fears could have been compounded by the impersonal and frightening atmosphere of a large tertiary hospital and the backdrop of an impending diagnosis of cancer. A number of interventions have been attempted to reduce this anxiety and improve adherence to follow-up appointments. These include information booklets, leaflets, video colposcopy and educational counselling. A recent Cochrane review by Galaal et al. ${ }^{4}$ found that video colposcopy may be effective in reducing anxiety when used before and after the abnormal cells are removed, and not during treatment - i.e. watching the actual surgical treatment was anxiety provoking.
In addition, our study found the mean trait anxiety score to be 46.81 (SD=9.50) with approximately half the patients having scores above than 50, indicating the likely presence of trait anxiety. This is considerably higher than most figures reported in similar studies performed elsewhere. Hellsten et al. ${ }^{10}$ reported a mean score of 36.6 (SD=10.2) in a study in Sweden and Gath et al. ${ }^{11}$ a mean score of 38.07 (SD=9.9) in a study in Oxford. Hellsten et al. ${ }^{8}$ also reported a significant rise in the level of anxiety in patients whose living, working and economic conditions were self-assessed as 'unsatisfactory'. It is likely that the women interviewed in our study face far harsher conditions than those in Sweden. $\mathrm{CHBH}$ is the only referral institution in Soweto and serves a vast urban population with a high unemployment rate (estimated at 23\% ${ }^{12,13}$ and a largely socially disadvantaged population, a legacy from the apartheid regimen. ${ }^{14}$ These high levels of trait anxiety may also be a consequence of the significant delay between when the appointment for colposcopy was made and the actual colposcopy itself. This interval may allow the anxieties related to the procedure to become pervasive and elevate trait anxiety scores. Finally, it is also reasonable to assume that an individual who is generally more anxious (i.e. trait) would also score highly in situational anxiety testing (i.e. state). No one simple suggestion within the scope of our study can hope to deal with all these factors, and until they are dealt with they will continue to compound the problems of anxiety associated with colposcopy and make investigation and treatment of an abnormal cervical smear a difficult task.

We also found that state anxiety scores were higher in younger patients, similar to the figures reported by Nugent et al..$^{9}$ It is possible that because older women have more life experience they are better able to deal with stressful situations. Furthermore, a woman who has already given birth to children might be less disturbed by the reproductive implications of a diagnosis of cervical cancer (possible hysterectomy) than a younger woman who has not yet completed her family. Ironically, the same factors that predispose to lower state anxiety scores may also cause raised trait anxiety scores. While older women tend to have had children and may therefore be less concerned about potential loss of the ability to have more, they are likely to be under considerable stress with regard to providing for their children and families and to worry a great deal about their continued well being.

Many of the factors associated with higher anxiety that were highlighted in other studies, such as being single, a low level of education and being unemployed, were not found to be significant in our study, probably because of the small sample 
size. Owing to their consistent appearance in these studies, however, we strongly suspect that they are important in our community as well and we believe that a further larger study may elicit some of these contributing factors.

This study focused on only one clinic, based in the Gauteng area. Further, patients already experiencing severe anxiety may have not kept their appointment for colposcopy and would therefore have not been included in this study. These factors may limit the extent to which the findings are applicable to the general population. While our findings are not generalisable, they do highlight the need for further investigation into this very important aspect of a commonly performed procedure.

\section{Conclusion}

Several studies have been done on the topic of anxiety associated with colposcopy, but very little information on our local population is available. This study reported significantly elevated trait anxiety scores relating to the procedure. This emphasises the need to identify the anxiety and to institute a plan through consultation-liaison psychiatry to ameliorate it with information booklets, leaflets, video colposcopy and educational counselling. This would help to improve the adherence to follow-up treatment and reduce the morbidity and mortality associated with cervical cancer.

\section{References}

1. Hays RD, Wells KB, Sherbourn CD, Rogers W, Spritzer K. Functioning and wellbeing outcomes of patients with depression compared with chronic general medical illnesses. Arch Gen Psychiatry 1995; 52: 11-19.

2. Druss BG, Rohrbaugh RM, Rosenheck RA. Depressive symptoms and health costs in older medical patients. Am J Psychiatry 1999; 156: 477-479.

3. Centre for Cancer Information. 1997. Colpscopy. www.cancerweb.ncl.ac.uk/cgibin/omd? query=colposcopy (accessed 21 April 2007).

4. Galaal K, Deane K, Sangal S, Lopes A. Interventions for reducing anxiety in women undergoing colpsocopy. Cochrane Database of Systematic Reviews 2007. CD006013. DOI: 10.1002/14651858.CD006013.pub2.

5. Coppleson M. Aetiology of squamous carcinoma of the cervix. Obstet Gynaecol 1968; 32: 432-436.

6. Mayo Clinic. Colposcopy: A follow-up to abnormal Pap test results. 2008. www. mayoclinic.com/health/colposcopy/WO00097 (accessed 16 June 2008).

7. Spielberger C. Manual for the State-trait Anxiety Inventory (Form Y). Palo Alto, Calif.: Consulting Psychologists Press, 1983: 121

8. Marteau T, Walker P. Anxieties in women undergoing colposcopy. BJOG 1990; 97: 859-861.

9. Nugent L, Tamlyn-Leaman K, Isa N, et al. Anxiety and the colposcopy experience. Clin Nurs Res 1993; 267-277.

10. Hellsten C, Sjostrom K, Lindqvist P. A prospective Swedish cohort study on psychosocial factors influencing anxiety in women referred for colposcopy. BJOG 2007; $114: 32-38$

1 1. Gath D, Hallum N, Mynors-Wallis L, et al. Emotional reactions in women attending a UK colposcopy clinic. J Epidemiol Community Health 1995; 49: 79-83

12. PO210 - Labour Force Survey (LFS). www.statssa.gov.za/keyindicators/ keyindicators.asp (accessed 16 August 2008).

13. Provincial Profile. Gauteng/Statistics South Africa. Health Systems Situation Analysis Report [Report No. 00-91-07 (1999)]. Pretoria: Statistics South Africa, 2003: 73 www. doh.gov.za/facts/eusites/sekhukhune04.pdf (accessed 16 August 2008).

14. Lund C, Flischer AJ. Norms for mental health services in South Africa. Soc Psychiatry Psychiatr Epidemiol 2006; 41 : 587-594. 